\section{Spastic Paralysis}

In these cases the slinging method, by removing some extraneous sources from which stimuli productive of spasm miay be derived, allows a development of power anid movement in the over-stretched opponents of the contracted muscles; it reduces the tension in the latter (contracted) muscular group to a minimum; in this particular connexion, perhaps the most important of all, it induces a condition of mental repose and the development of a " plastic mind," both highly beneficial to the patient's general condition and also conducive to the production of a regular and rhythmic type of movement. Figure D illustrates the general relaxation position.

\section{Conclusions}

1. The relaxation treatment encourages a mental and a local physical condition conducive to the restoration of normal function in the affected part by instilling into the patient the necessity and ability to rest the central cerebral processes and to develop a " plastic mind."

2. The possibility of producing a maximal movement with a minimal muscle effort lessens the risk of fatigue in a weakened muscle group.

3. The removal of extraneous forces, in particular, gravity, the weight of the limb, and friction, leads to the abolition of fear, with its concomitant involuntary spasm, and to the growth of confidence, with consequent ability to assist voluntarily the restoration processes.

\section{A SAFE METHOD OF DEALING WITH ETHMOIDITIS *}

\section{BY}

E. A. PETERS, M.D., F.R.C.S.

SURGEON, ROYAL EAR HOSPITAL, UNIVERSITY COLLEGE HOSPITAL, AND BOLINGBROKE HOSPITAL

The dangers of ethmoidal operations are considerable, and are often due to extension of the infection along the perineural sheath of the olfactory nerves or damage to the cribriform plate. There are also the dangers due to an accompanying sinus suppuration. Infection of the frontal sinus, however, gives an indication of its existence by the locality of the pain, and sphenoidal empyema may also be present, a disease dangerous in its closed form and characterized by. most indefinite symptoms. Bacteria in the sphenoidal cavity have the power of passing through bone or infecting the meningeal network by some inconstant route.

I would urge that in all cases of ethmoiditis, except simple polypus, radiograms should be taken to obtain information as to the infection of the sinuses, and, if the radiogram is doubtful, that the particular sinus should be drained by the intranasal method. Radiographic pictures of the frontal sinus are usually definite; the evidence of infection of the maxillary antrum is less clear, and that of empyema of the sphenoidal sinus is extremely indefinite. I suggest that primary ethmoiditis operations should, except for simple polypus, consist in removal of the middle turbinal bone with intranasal drainage of the sphenoidal and the maxillary antra. The frontal sinus should be dealt with at the same time by intranasal or external operation if the radiograms and symptoms indicate infection. I am in touch with a patient in whom all six sinuses were opened for early ethmoiditis ten years ago; pus was present in one sphenoidal sinus and in the frontal sinus of the other side. The ethmoiditis has completely subsided.

* Read in the Section of Laryngology and Otolcgy at the Annual Meeting of the British Medical Association, Winnipeg, 1930
The middle turbinal varies very much in structure. In some cases it consists of a lamina, but in others it contains a small or expanded middle ethmoidal cell causing pressure symptoms on the septum when the cell is expanded. It is possible that this pressure when combined with rhinitis may be a factor, for it is this cell type of middle turbinal which undergoes polypoid change; and though the supporters of the "from within theory". may be assisted by some special character of the bone itself, it would appear that it is only in the case of thin laminae of bone, in which periosteum and mucous membrane are closely combined, that inflammation of the mucous membrane leads to osteitis, constituting ethmoiditis. The degree varies from the local change resulting in simple polypus to the common condition of rarefying osteitis with polypi and a varying amount of pus to the extensive form occasionally seen in fevers of acute infection with disintegration of the ethmoid into granulation and pus. Under these conditions the inferior turbinal, consisting of spongy bone, develops hypertrophic rhinitis, and I have seen a middle turbinal of structure similar to an inferior turbinal which merely developed a hypertrophic rhinitis like that of the inferior turbinal.

\section{Removal of Turbinal Bones}

Removal of the middle turbinal by Luc's forceps should be carried out either in its entirety by gripping the body of the bone, or by " nibbling " from the anterior end and removing the opened cell. In this way the landmark of attachment of the turbinal is preserved with a view to the opening of cells in the fronto-nasal and agger nasi regions situated at the anterior attachment of the middle turbinal; these are easily opened by the gouge and mallet. It is, as a rule, necessary only to carry out occasional trimmings of polypi under a local anaesthetic from time to time, and to open cells only if the symptoms of discomfort due to closed empyemata appear. Extensive opening of these cells is rarely indicated. Sir StClair Thomson mentions that the opening of the higher cells is fraught with danger. Even removal of the middle turbinal may be a danger.

A man, aged 38, suffered from nasal obstruction. Both the radiogram and the symptoms showed frontal sinus infection. The nasal cavities were filled with oedematous polypi, a small amount of muco-pus being present. A softened middle turbinal was removed from either side and the antrum was opened. On the second day he complained of a severe headache, and died of meningitis. On one side the cribriform plate showed a small erosion from which the softened mucous membrane came away, probably with the turbinal.

This condition would possibly have been fatal in any case, and certainly in any extensive ethmoid removal.

\section{Frontal Sinus}

It is rarely necessary to drain this without radiographic or symptomatic indications; if such exist, an intranasal operation should preferably be carried out, special attention being directed to the fronto-nasal and agger nasi cells (anterior ethmoidal group) by applying gouge and mallet to the part immediately anterior to the attachment of the middle turbinal. (This should be done before removal of the middle turbinal.) Infection of these cells is closely interwoven with latent frontal sinusitis, and even with that variety in which the pain is removed by the application of a pledget of wool soaked in 10 per cent. cocaine solution. The maxillary antrum should be drained intranasally in most cases of extensive polypi, an opening being made by Tilley's frontal sinus burr; the aperture can then be enlarged by Luc's forceps. It is usually advisable to remove the anterior end of the inferior 
turbinal. The mucous membrane of the sinus is commonly in the same condition as that of the nose; latent or maxillary empyema is excluded by drainage ; the consequent effect on the ethmoiditis is good.

Closed sphenoidal empyema gives rise to a series of indefinite symptoms of malaise and pain at the back of the head.

A woman was admitted to hospital for relief of nasal obstruction and removal of septic tonsils. For some years she had had malaise, debility, and catarrhal laryngitis. A radiogram of the chest indicated absence of phthisis, and that of the head showed opacity in the right ethmoid region. No pus was observed on nasal and post-nasal examination. At the operation both middle turbinals were removed. The middle ethmoidal cells were well developed, but did not contain fluid. The septic tonsils were also removed. Three days later the patient developed fever, and a haemolytic streptococcus was isolated from the inflamed pharynx. Anti-scarlet fever serum, collosol manganese, and hypertonic saline were given, and apparently complete recovery took place. Two weeks later a similar attack of fever recurred. Meningitis supervened, and she died four days after this relapse.

In this case neither maxillary sinus nor sphenoidal sinus was opened at the time of operation, as no pus was seen, and it seemed advisable not to expose a feeble individual to further manipulation. The presence of haemolytic streptococci seemed to contraindicate any further intervention in the absence of definite symptoms in the second phase. Yet if the sinus had been opened, her life would have been saved.

\section{Opening the Sphenoidal Sinus}

In opening the sphenoidal sinus I usually employ the method introduced by $P$. Watson-Williams; it is applicable whether the field is obscured by blood or not.

The anaesthetized patient lies on the left side, or sits up. The left forefinger is introduced through the mouth into the post-nasal space, defining the top of the septum nasi. A steel probe introduced through the nostrils touches the forefinger, and is advanced about $1 / 4$ inch anterior and about $1 / 4$ inch from the middle bone. Careful and controlled pressure on the thin bone in front of the dense vomerine ridge perforates the bone or osteum and admits the steel probe into the cavity of the sphenoid. This opening is further enlarged by a narrow gouge, and finally by punch forceps or raspatory. The posterior ethmoid is cautiously opened if necessary. If the middle turbinal has been removed, the enlarged opening of the sphenoid can be observed with a nasal speculum. I have found that Rouge's method gives a better view than lateral rhinotomy when direct manipulation is advisable.

I would suggest that sinus radiography should be carried out in all cases of ethmoiditis, and that the basis of operation should be removal of the middle turbinal, drainage of the sphenoidal sinuses and maxillary antrum; and of the frontal sinuses, if the radiographic examination indicates such a course. This treatment, followed later by removal of polypi under local anaesthesia, and possibly the opening of cells from below the attachment of the middle turbinal, is advised.

\section{A NOTE ON THE TREATMENT OF ERYSIPELAS BY X RAYS}

\section{With an Account of Three Cases}

BY

\section{R. HILLHOUSE JAMIESON, M.D., F.R.C.S.ED. SUTTON, SURREY \\ AND}

F. HERNAMAN-JOHNSON, M.D., D.M.R.E.

RADIOLOGIST, FRENCH HOSPITAL, LONDON; PHYSICIAN IN CHARGE, X-RAY DEPARTMENT, CROYDON GENERAL HOSPITAL

The value of $x$-ray therapy as an agent capable of cutting short the acute stage of erysipelas does not appear to be well known in this country, although it was advocated in America some years ago by Platau, Schlitz, and Collins. ${ }^{1}$ An account of the following three cases which recently occurred consecutively in the private practice of one of us (R. H. J.) may therefore prove of interest. The first is quoted as exemplifying the use of local applicaticns and serum, but no $x$ rays.

\section{CASE I}

A man, aged 63 , received a gnat bite on the ear. On May 28th the ear swelled to about three times its usual size; the inflammatory swelling spread slowly over the face, scalp, and forehead. Nothing stopped it, but continuous application of a saturated solution of Epsom salts gave most relief. Ichthyol was disappointing, and once, after its application, the temperature ran up, and the patient had a rigor. Antistreptococcus serum gave no definite result. Ultimately the temperature dropped after fifteen days of a trying illnesstrying to both doctor and patient.

Distressing though the attack was, the temperature did not rise at any time above $101.6^{\circ} \mathrm{F}$.; whereas in the two cases next described the temperature reached $103^{\circ}$ before $x$ rays were applied. Note that the temperature in the first case shows a fall by lysis; in the other two a fall by crisis, immediately following the first application of the $x$ rays.

\section{CASE II}

The patient was a man, aged 40. The attack in this instance started sharply, without apparent cause, such as insect bite or an irritated pimple. It soon involved the whole face and scalp, and began to spread down the neck on the right side. The application of Epsom salts solution locally made the patient feel more comfortable. Serum was administered on the morning of the third day, and repeated the two following days. Twelve hours after the last injection of serum the temperature rose to $103^{\circ}$. On the evening of the seventh day of the attack it was still $102.6^{\circ}$. The patient felt very ill, and was very despondent. It was at this point that it was decided to try $x$ rays. A portable set was employed, working on the electric light mains. The temperature showed a drop in less than twelve hours to $99.4^{\circ}$, rose to $99.6^{\circ}$ the same evening, but the following morning (ninth day) it was normal. $X$ rays were omitted on the twelfth day, as the temperature remained normal but a rise to $99.2^{\circ}$ on the thirteenth day seemed to call for a further $x$-ray exposure. After this there was no more fever.

The improvement in this patient's general and local condition after the $x$-ray application was most dramatic. The third case need not be gone into in detail, as it was of very short duration.

\section{CASE III}

A married woman, aged 62, suffered from an acute attack of facial erysipelas, following on tonsillitis. The patient was very debilitated, and could not be induced to take nourishment. On the fourth day her whole face and parts of tho scalp were red and swollen, and some blisters were present. The disease was spreading. The first dose of $x$ rays was administered at 9 p.m. Next morning the temperature was normal, and did not again rise above $98.8^{\supset} . X$-ray treatment was given on three successive days.

\section{Comment}

We feel that in $x$ rays there is to hand a powerful weapon against the disease under discussion. The contrast between the first case, taking its slow and painful course despite all the usual remedies, and the other two, is very remärkable. The two latter were more severe 